\title{
Potencial metanogênico de resíduos de frutas e hortaliças em função do tipo de inóculo
}

O objetivo deste trabalho foi avaliar o potencial de produção e a qualidade do biogás a partir da biodigestão anaeróbia de resíduos de frutas e hortaliças (RFH) como substrato e duas fontes distintas de inóculo como fonte de biomassa bacteriana. Os resíduos foram coletados em uma Central de Abastecimento e os inóculos incluíram lodo anaeróbio secundário coletado em uma estação de tratamento de esgoto sanitário (inóculo/ES) e lodo anaeróbio coletado em um biodigestor abastecido com dejetos suínos (inóculo/DS). A determinação do potencial de produção de biogás foi realizada seguindo as diretrizes propostas pela norma VDI 4630. O volume de biogás foi medido diariamente e a composição determinada semanalmente por cromatografia gasosa. Os RFH apresentaram pH ácido, ausência de alcalinidade, elevada umidade e elevada concentração de material orgânico volátil. Os inóculos apresentaram pH próximo à neutralidade, resultante de processos anaeróbios bem estabilizados e a principal diferença foi observada para os teores de alcalinidade. A produção acumulada de biogás dos RFH foi de 362 mLN g SV-1 utilizando o inóculo/ES e 348 mLN g SV-1 utilizando com inóculo/DS, indicando similaridade independentemente do tipo de inóculo. No entanto, observaram-se diferenças quanto à produção diária e à concentração de metano. A utilização do inóculo/ES possibilitou a rápida conversão da matéria orgânica em biogás, com aproximadamente $90 \%$ da produção total gerada nos primeiros quatro dias. Os testes com o inóculo/DS apresentaram $60 \%$ de metano (totalizando $210 \mathrm{mLN}$ CH4 g SV-1) e os testes com inóculo/ES 51\% de metano (totalizando $184 \mathrm{mLN} \mathrm{CH} 4 \mathrm{~g} \mathrm{SV}-1$ ). Mesmo com maior capacidade de degradação durante o processo, o inóculo/DS permitiu uma produção acumulada de metano $14 \%$ superior quando comparada ao inóculo/ES.

\section{Methanogenic potential of residues of fruits and vegetables depending on the type of inoculum}

\begin{abstract}
The objective of this work was to evaluate the potential and quality of biogas production from anaerobic digestion, using fruit and vegetable waste (FVW) as substrate and two different sources of inoculum as a source of bacterial biomass. The residues were collected at a Food Supply Center and the inocula included secondary anaerobic sludge collected at a wastewater treatment plant (ES/inoculum) and anaerobic sludge collected in a biodigestor that treats swine manure (DS/inoculum). The determination of the biogas production potential was carried out following the guidelines proposed by the VDI 4630 . The biogas volume was measured daily and the composition determined weekly by gas chromatography. The FVW had acid pH, absence of alkalinity, high humidity and high concentration of volatile organic material. The inocula presented pH close to neutrality, resulting from well-stabilized anaerobic processes and the main difference was observed for the alkalinity contents. The accumulated biogas production of the FVW was $362 \mathrm{mLN}$ g SV-1 using the ES-inoculum and $348 \mathrm{mLN} g$ SV-1 using DS/inoculum indicating similarity regardless of the type of inoculum. However, there were differences in daily production and methane concentration. The use of ES/inoculum allowed the rapid conversion of organic matter into biogas, with approximately $90 \%$ of the total production generated in the first four days. Testing with the DS/inoculum showed 60\% methane (totaling $210 \mathrm{mLN} \mathrm{CH} 4 \mathrm{~g} \mathrm{SV}-1$ ) and with the ES/inoculum showed 51\% (totaling $184 \mathrm{mLN} \mathrm{CH4} \mathrm{g} \mathrm{SV-1).} \mathrm{Even} \mathrm{with} \mathrm{higher}$ degradation capacity during the process, DS/inoculum allowed a cumulative production of methane $14 \%$ higher when compared to ES/inoculum.
\end{abstract}

Keywords: Anaerobic Digestion; Sewage Sludge; Pig Manure; Methane; Organic Waste.

Topic: Engenharia Sanitária

Reviewed anonymously in the process of blind peer.
Received: $14 / 12 / 2017$

Approved: 24/01/2018

Thiago Edwiges (iD)

Universidade Tecnológica Federal do Paraná, Brasil http://lattes.cnpq.br/7643832070860943

http://orcid.org/0000-0002-6691-8100

thiagoe@utfpr.edu.br

Mônica Sarolli Silva de Mendonça Costa (i)

Universidade Estadual do Oeste do Paraná, Brasil

http://lattes.cnpq.br/2379457318731477

http://orcid.org/0000-0001-9514-1727

monica.costa@unioeste.br

\section{Laercio Mantovani Frare (iD}

Universidade Tecnológica Federal do Paraná, Brasil

http://lattes.cnpq.br/7676033878331606

http://orcid.org/0000-0002-6367-0023

laercio@utfpr.edu.br

d

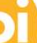

DOI: 10.6008/CBPC2179-6858.2018.002.0016

João Henrique Lima Alino (iD)

Universidade Tecnológica Federal do Paraná, Brasi

http://lattes.cnpq.br/6012375307745600

http://orcid.org/0000-0002-1495-0416

joaoalino94@gmail.com

Bruna Mayer (ic

Universidade Tecnológica Federal do Paraná, Brasil

http://lattes.cnpq.br/2093279095595256

http://orcid.org/0000-0002-5085-5838

brunamayer@live.co.uk

Referencing this:

EDWIGES, T.; COSTA, M. S. S. M.; FRARE, L. M.; ALINO, J. H. L.; MAYER,

B.. Potencial metanogênico de resíduos de frutas e hortaliças em

função do tipo de inóculo. Revista Ibero Americana de Ciências

Ambientais, v.9, n.2, p.185-194, 2018. DOI:

http://doi.org/10.6008/CBPC2179-6858.2018.002.0016 


\section{INTRODUÇÃO}

O crescimento dos centros urbanos impulsionado pelas oportunidades econômicas tornou o escoamento da produção rural, principalmente de produtos hortigranjeiros, mais complexo e oneroso. Este crescimento aumentou a necessidade de aperfeiçoamento das estruturas de comercialização deste tipo de produto. Assim, a partir de 1970 a implantação de Centrais de Abastecimento (Ceasa) nos principais centros urbanos do país foi estabelecida como prioridade, por meio do Programa Estratégico de Desenvolvimento.

As unidades atacadistas passaram a se constituir em efetivos centros de comercialização de produtos hortigranjeiros, possibilitando maior eficiência quanto à organização do setor, de modo a incentivar a produção hortícola e facilitar o intercâmbio entre os centros consumidores. A Ceasa/PR possui cinco unidades e ocupa o quarto lugar em relação ao comércio de hortigranjeiros, com movimentação de 1.083 .868 toneladas de alimentos em 2012, envolvendo em torno de 5.000 produtores e 700 comerciantes.

Por outro lado, a natureza das atividades comerciais desenvolvidas na Ceasa caracteriza estas unidades como grandes geradoras de resíduos sólidos. O alto nível de desperdício dos produtos comercializados ocorre devido à falta de cuidado com o manuseio ainda no campo e do transporte em caminhões sem sistema de refrigeração, danificando os produtos mesmo antes de chegarem ao destino final.

A Política Nacional de Resíduos Sólidos, que visa disciplinar o gerenciamento dos resíduos, prevê a erradicação de lixões e destaca a busca por soluções alternativas de gerenciamento (BRASIL, 2010). Tais soluções compreendem processos biológicos e térmicos de tratamento, bem como a adequada disposição final, ambas com vantagens e desvantagens relacionadas aos custos e a possibilidade de recuperação de nutrientes e energia.

O sistema de compostagem oferece benefícios ao tratamento de resíduos orgânicos como redução de volume e eliminação de microrganismos patogênicos, porém, possui limitações quanto ao tempo de degradação e disponibilidade de nutrientes para ajustar a relação carbono e nitrogênio para determinados tipos de biomassa (PETRIC et al., 2012). A incineração é um sistema eficiente de tratamento de resíduos sólidos que possibilita a recuperação energética. No entanto, esta tecnologia apresenta elevados custos operacionais, gera emissões atmosféricas preocupantes e requer baixa umidade dos resíduos a serem tratados. Já os sistemas de disposição final em aterros sanitários, além de não configurarem um sistema de tratamento, podem gerar impactos ambientais significativos, tanto no solo, quanto nos recursos hídricos e atmosfera, mesmo após o seu encerramento (RABL et al., 2008).

Uma alternativa viável para o tratamento de diversos tipos de resíduos orgânicos, tanto no estado sólido quanto líquido é a utilização de processos de digestão anaeróbia (NEVES et al., 2006; YEN et al., 2007). Além de possibilitar a recuperação energética dos resíduos tratados, a digestão anaeróbia produz um fertilizante natural, capaz de recuperar solos degradados (GOMEZ-LAHOZ et al., 2007).

A digestão anaeróbia é um processo complexo, que pode ser dividido em quatro fases de degradação, como a hidrólise, acidogênese, acetogênese e metanogênse. Estas quatro fases individuais ocorrem na presença de diferentes grupos de microrganismos, que permanecem em simbiose parcial e exigem requisitos 
distintos do ambiente (DEUBLEIN et al., 2008). A influência do tipo de inóculo em testes de batelada está relacionada à origem do inóculo; concentração de microrganismos, que em determinado nível de limitação, pode ser medida indiretamente pelo teor de sólidos voláteis e aclimatação do inóculo ao tipo de substrato a ser digerido. Desta maneira, variações no resultado final do potencial de metano são resultantes do tipo de inóculo utilizado, visto que diferentes fontes de inóculo resultam em diferentes taxas de biodegradabilidade como consequência de diferentes níveis de população microbiana (RAPOSO et al., 2011).

Assim, um consórcio de microrganismos ativos e adaptados contribuem diretamente para a eficiência da biodigestão anaeróbia. $\mathrm{O}$ balanço de nutrientes também é um fator crítico para o processo, que requer relação carbono/nitrogênio (C/N) entre 20-30 para a otimização da produção de biogás (FORSTER-CARNEIRO et al., 2008). Enquanto o excesso de nitrogênio pode provocar a inibição da atividade bacteriana, a falta deste nutriente pode limitar degradação, resultando em um potencial reduzido de produção de biogás. Desta forma, este trabalho teve como objetivo avaliar a produção e a qualidade do biogás a partir da biodigestão anaeróbia utilizando resíduos de frutas e hortaliças (RFH) como substrato e duas fontes distintas de inóculo como fonte de biomassa bacteriana.

\section{MATERIAIS E MÉTODOS}

\section{Obtenção do substrato e inóculo}

Para avaliar o potencial de produção de biogás foi utilizado como substrato uma amostra da fração orgânica dos resíduos sólidos gerados na CEASA - Unidade Atacadista de Foz do Iguaçu/PR. Foram coletados aproximadamente $10 \mathrm{~kg}$ de resíduos de frutas e hortaliças (RFH), compostos por sobras de pepino, tomate, pêssego, nectarina, laranja, berinjela, ameixa, repolho, acelga, banana, mamão, maçã, abobrinha, chuchu, cenoura, limão, uva e melancia.

Para garantir a homogeneidade da amostra, os resíduos foram processados em liquidificador industrial sem adição de água (Poli LS-10) até diâmetro de partícula inferior a $10 \mathrm{~mm}$, conforme recomendação da norma VDI 4630 (2006). Uma fração da amostra in natura foi utilizada para determinação de pH, sólidos totais (ST) e sólidos voláteis (SV) conforme APHA (2005). Já as determinações de alcalinidade total (AT) foram realizadas a partir da metodologia proposta por Rippley et al. (1986).

Uma fração da amostra foi seca a $60 \pm 2{ }^{\circ} \mathrm{C}$ em estufa com circulação forçada de ar e processada em moinho tipo Willey (Tecnal TE-680) para a determinação de nitrogênio total Kjeldahl (NTK) conforme proposto por Malavolta et al. (1989). A estimativa do carbono orgânico total (COT) foi realizada dividindo-se o teor de SV pelo fator 1,8 (KIEHL, 1985). A relação C/N foi obtida a partir da divisão dos valores de COT pelos valores de NTK.

Para os testes de biodigestão anaeróbia foram utilizados dois tipos de inóculo como fonte de biomassa bacteriana. Uma amostra de lodo anaeróbio secundário foi coletada em uma estação de tratamento de esgoto sanitário (ETE), na cidade de Foz do Iguaçu/PR, que utiliza Reator Anaeróbio de Leito Fluidizado (RALF) como tratamento biológico, sendo denominada de inóculo/ES. Uma segunda amostra de 
lodo anaeróbio foi coletada em um biodigestor de fluxo tubular, em uma propriedade agrícola localizada no município de São Miguel do Iguaçu/PR, que trata dejetos gerados pela criação de suínos, sendo esta denominada de inóculo/DS.

\section{Aparato experimental para os ensaios em batelada}

A determinação do Potencial Metanogênico Específico (PME) dos RFH foi realizada a partir da biodigestão anaeróbia em batelada (Figura 1). Na Figura 1 pode-se observar uma representação do sistema utilizado, assim como a legenda com a identificação de suas partes ou características identificadas pelas letras de $\mathrm{A}$ até $\mathrm{H}$. O sistema foi composto por reatores de vidro com $200 \mathrm{~mL}$ de volume útil (A) e $95 \mathrm{~mL}$ de headspace, tubos eudiômetros (B) com volume de $350 \mathrm{~mL}$ e frascos de nível de $1 \mathrm{~L}$ (G). Um tubo de conexão (C) interno ao eudiômetro conecta o reator (A) para que o volume de gases produzidos possa ser medido. De acordo com a produção de gás, ocorre o deslocamento do volume do líquido interior ao eudiômetro. 0 volume de líquido deslocado a partir da pressão gerada pelo biogás era coletado em recipientes de vidro (G) conectados aos eudiômetros. A ligação entre o eudiômetro e o frasco de vidro era feita por meio de mangueiras de silicone (F). Assim que o volume de gás produzido se aproximava de $350 \mathrm{~mL}$, este era coletado, para análise ou para descarte, por meio de uma válvula $(\mathrm{H})$. Todos os testes em batelada foram realizados em triplicata.

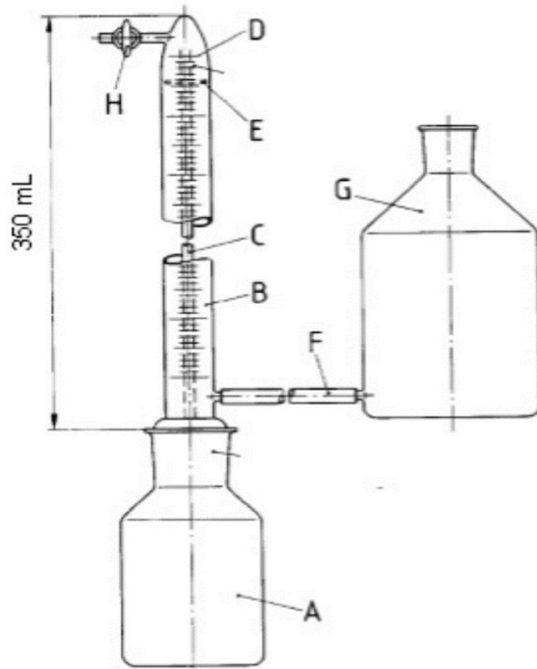

Legenda

A) frasco com amostra

B) tubo eudiômetro com graduação de 1

$\mathrm{mL}$

C) tudo de conexão com diâmetro de 6

$\mathrm{mm}$

D) marca zero

E) separador entre tubo interior e exterior

F) mangueira de silicone para conexão

entre os frascos

G) recipiente de nível

H) válvula para amostragem de gases

Figura 1: Esquema do reator, eudiômetro e frasco de nível utilizados para o teste de PME. Fonte: Adaptado de DIN 38414-8 (1985).

Para a realização dos experimentos foram utilizados doze conjuntos de eudiômetros, reatores e frascos de nível (Figura 1). Destes, três foram preenchidos com cada tipo de inóculo e água destilada (denominados de controle) para determinar a produção endógena de biogás e três preenchidos com cada tipo de inóculo e substrato. Todos os reatores foram mantidos a uma temperatura controlada de $35 \pm 2{ }^{\circ} \mathrm{C}$ por meio de um banho termostático. O volume de biogás gerado nos reatores controle foi descontado dos reatores contendo o substrato e o inóculo, visando a expressão dos resultados específicos do substrato. Para a realização dos experimentos foram adotadas as condições estabelecidas pela norma VDI 4630 (Tabela 1). 
Tabela 1: Condições de operação dos reatores em todos os experimentos.

\begin{tabular}{|l|l|l|l|}
\hline Parâmetro & Recomendação da norma VDI 4630 & Substrato + inóculo/ES & Substrato + inóculo/DS \\
\hline Teor de ST no reator & $\leq 10,0 \%$ & $4,09 \%$ & $3,50 \%$ \\
\hline Teor de SV no reator & 1,5 a $2,0 \%$ & $1,85 \%$ & $1,94 \%$ \\
\hline SV inóculo / SV substrato & $\geq 2,0 \%$ & 4,0 & 4,1 \\
\hline
\end{tabular}

\section{Determinação do volume e composição do biogás produzido}

O monitoramento do sistema foi realizado a partir do registro diário da produção de biogás $(\mathrm{mL})$, pressão atmosférica $(\mathrm{mm} \mathrm{Hg})$ e temperatura ambiente $\left({ }^{\circ} \mathrm{C}\right)$. O monitoramento foi mantido até que o incremento do volume diário de biogás fosse menor que $1 \%$ do volume acumulado (VDI, 2006). Os volumes gerados de biogás foram expressos e $\mathrm{mL} \mathrm{g} \mathrm{SV}^{-1}$ e padronizados conforme as condições normais de temperatura e pressão (Equação 1).

$$
\text { Eq. } 1 \quad V_{0}=V \frac{\left(P_{L}-P_{W}\right) T_{0}}{P_{0} T}
$$

Em que $V_{o}$ é o volume de biogás padronizado $\left(m L_{N}\right)$; $V$ é o volume de biogás registrado no eudiômetro $(\mathrm{mL})$; $\mathrm{P}_{\mathrm{L}}$ é a pressão atmosférica no momento do registro (mbar); $\mathrm{P}_{\mathrm{w}}$ é a pressão de vapor da água (mbar); $\mathrm{T}_{0}$ é a temperatura padrão (273 K); $\mathrm{P}_{0}$ é a pressão padrão (1013 mbar) e T é a temperatura ambiente (K). A pressão de vapor $(\mathrm{Pw})$ foi considerada visando obter medidas mais precisas de produção de biogás (STRÖMBERG et al., 2014). Devido às medições ocorrerem em temperatura ambiente, esta foi considerada como a temperatura do gás e não a temperatura dentro do reator. O cálculo da pressão de vapor de água foi realizado considerando a Equação 2 .

Eq. $2 \quad \mathrm{P}_{\mathrm{W}}=10^{8,1962}-\frac{1.730,63}{\mathrm{~T}-39,724}$

A composição do biogás foi determinada por cromatografia gasosa (ASTM D1945-14, 2014) em cromatógrafo (Perkin Elmer - Clarus 680) com Detector de Condutividade Térmica (TCD), coluna empacotada Plot $Q$, com $30 \mathrm{~m}$ de comprimento e diâmetro interno de 0,32 mm, utilizando hélio como gás de arraste com fluxo de $30 \mathrm{~mL} \mathrm{~min}^{-1}$. A rampa de temperatura do forno foi programada para aumentar de 32 a $1.000{ }^{\circ} \mathrm{C}$ com taxa de $200^{\circ} \mathrm{C} \mathrm{min}-1$ e tempo de espera final de $2 \mathrm{~min}$.

Tabela 2: Composição do biogás sintético.

\begin{tabular}{|l|l|l|l|l|l|l|}
\hline Biogás Sintético & $\mathbf{C H}_{\mathbf{4}} \mathbf{( \% )}$ & $\mathbf{C O}_{\mathbf{2}} \mathbf{( \% )}$ & $\mathbf{H}_{\mathbf{2}} \mathbf{S}(\mathbf{p p m})$ & $\mathbf{O}_{\mathbf{2}} \mathbf{( \% )}$ & $\mathbf{H}_{\mathbf{2}} \mathbf{( \% )}$ & $\mathbf{N}_{\mathbf{2}} \mathbf{( \% )}$ \\
\hline Padrão A & 90,0 & 9,70 & 3.000 & - & - & - \\
\hline Padrão B & 55,0 & 44,3 & 7.000 & - & - & - \\
\hline Padrão C & 55,0 & 41,0 & 5.000 & 3,0 & 0,25 & 0,25 \\
\hline
\end{tabular}

Uma alíquota de biogás foi amostrada diretamente de uma saída no tubo eudiômetro (válvula) e 0,5 $\mathrm{mL}$ foram injetados no equipamento, utilizando seringa de vidro (Hamilton - Gastight). Nos cromatogramas obtidos, foram identificadas as frações de metano $\left(\mathrm{CH}_{4}\right)$, dióxido de carbono $\left(\mathrm{CO}_{2}\right)$ e sulfeto de hidrogênio $\left(\mathrm{H}_{2} \mathrm{~S}\right)$. A calibração do equipamento foi realizada utilizando-se biogás sintético (White Martins) de composição conhecida. Foram construídas curvas de concentração molar de $\mathrm{CH}_{4}, \mathrm{CO}_{2}$ e $\mathrm{H}_{2} \mathrm{~S}$ em função da 
área a partir de diferentes diluições dos padrões do biogás sintético. A composição dos gases utilizados na calibração do equipamento é apresentada no Tabela 2.

\section{RESULTADOS E DISCUSSÃO}

\section{Caracterização do substrato e dos inóculos}

As amostras de RFH e dos dois tipos de inóculo foram caracterizadas a partir de parâmetros físicos e químicos para avaliar a viabilidade técnica para a biodigestão anaeróbia (Tabela 3).

Tabela 3: Caracterização física e química do substrato e dos inóculos.

\begin{tabular}{|l|l|l|l|l|}
\hline Parâmetro & Amostra de RFVL & Inóculo/ES & Inóculo/DS & Unidade \\
\hline $\mathrm{pH}$ & $4,30 \pm 0,05$ & $6,44 \pm 0,1$ & $7,96 \pm 0,01$ & - \\
\hline Alcalinidade Total & $\leq 20$ & $1.701 \pm 26$ & $20.610 \pm 180$ & $\mathrm{mg} \mathrm{CaCO}_{3} \mathrm{~L}^{-1}$ \\
\hline Condutividade Elétrica & $1,3 \pm 0,05$ & $1,6 \pm 0,1$ & $17,5 \pm 0.2$ & $\mathrm{mS} \mathrm{cm}^{-1}$ \\
\hline Sólidos Totais & $8,7 \pm 0,2$ & $8,4 \pm 0,2$ & $7,2 \pm 0,1$ & $\%$ \\
\hline Sólidos Voláteis & $91,2 \pm 0,3$ & $51,8 \pm 0,1$ & $65,2 \pm 0,1$ & $\% \mathrm{ST}$ \\
\hline Carbono Orgânico Total & $50,6 \pm 0,2$ & $28,8 \pm 0,1$ & $36,2 \pm 0,1$ & $\% \mathrm{ST}$ \\
\hline Nitrogênio Total Kjeldahl & $1,8 \pm 0,02$ & $2,7 \pm 0,03$ & $2,7 \pm 0,04$ & $\% \mathrm{ST}$ \\
\hline Relação C/N & $10,7 \pm 0,2$ & $13,4 \pm 0,1$ & - \\
\hline
\end{tabular}

Observa-se que os RFH apresentaram pH ácido para processos de biodigestão anaeróbia. Valores similares de 4,2 e 5,8 foram registrados por Lin et al. (2011) e Jiang et al. (2012), respectivamente. Ward et al. (2008) recomendam valores entre 6,8 a 7,2 para a bom desempenho da atividade bacteriana. Em função do $\mathrm{pH}$ abaixo de 4,5 não se observa presença de alcalinidade ( $\leq 20 \mathrm{mg} \mathrm{CaCO}_{3} \mathrm{~L}^{-1}$ ) do resíduo, ou seja, faz-se necessária a utilização de um inóculo capaz de suprir esta demanda e garantir o efeito tampão do reator durante o processo. Assim, é possível evitar que ácidos graxos resultantes da decomposição de carboidratos solúveis possam acarretar em quedas bruscas de $\mathrm{pH}$.

Quanto aos teores de sólidos, os RFH apresentaram 8,7\% ST e 91,2\% SV, indicando elevada umidade e concentração de material orgânico volátil com potencial para conversão em biogás. Valores similares de 7,4\% ST; $87,8 \%$ SV e 3,7\% ST; 90,2\% SV para este tipo de substrato foram encontrados por Lin et al. (2011) e Li et al. (2013), respectivamente. Além dos sólidos voláteis, a relação C/N complementa o diagnóstico de viabilidade técnica para a biodigestão anaeróbia, demonstrando adequado grau de degradabilidade do material, haja vista o valor próximo ao recomendado para este tipo de substrato entre 22 a 25 (BOUALLAGUI et al., 2009).

Quanto aos dois tipos de inóculos testados, o pH próximo à neutralidade resulta de processos bem estabilizados quanto aos reatores anaeróbios. No entanto, de acordo com o protocolo para a determinação de PME publicado por Holliger et al. (2016), valores ideais de pH estão entre 7,0 a 8,5, indicando maior adequabilidade do inóculo/DS, que apresentou pH de 7,96 (Tabela 3). Além disso, a alcalinidade total do inóculo/DS também foi superior à registrada para o inóculo/ES, sendo o primeiro dentro do recomendado entre 2.500 a $5.000 \mathrm{mg} \mathrm{CaCO}_{3} \mathrm{~L}^{-1}$ (RAPOSO et al., 2011) para promover maior capacidade de efeito tampão, permitindo a acumulação de AGV com um mínimo de queda no pH.

A condutividade elétrica do inóculo/DS apresentou-se mais elevada se comparada ao inóculo/ES e ao substrato, devido principalmente à maior presença de sais neste tipo de efluente em função do processo 
produtivo e sistema de higienização. No entanto, não são encontrados valores de referência na literatura que possam embasar a discussão com base neste parâmetro. Por fim, o teor mínimo de $50 \%$ de SV dos dois tipos de inóculo foi atendido, de acordo com os requisitos propostos pela norma VDI 4630 (2006).

\section{Potencial de produção de biogás}

A produção diária de biogás do inóculo/DS sem adição de RFH foi elevada durante as primeiras 24 horas após a incubação, com $25 \%$ da produção total durante este período, seguindo uma tendência à estabilização durante os demais dias (Figura 2a). A produção acumulada de biogás deste inóculo foi de 91 $\mathrm{mL}_{\mathrm{N}}$ biogás $\mathrm{g} \mathrm{VS}^{-1}$ (Figura 2b). Este comportamento revela o elevado teor de carboidratos facilmente hidrolisáveis presente neste tipo de inóculo. Já a produção diária de biogás do inóculo/ES foi baixa nas primeiras 24 horas, com posterior aumento até o oitavo dia (Figura 2a), possivelmente devido à presença de proteínas e lipídeos que requerem maior tempo para a hidrólise. A produção acumulada de biogás do inóculo/ES foi de $184 \mathrm{~mL}_{\mathrm{N}}$ biogás $\mathrm{g} \mathrm{SV}^{-1}$ (Figura 2b). Aos quinze dias de incubação ambos os inóculos apresentaram produção diária de biogás inferior à $1 \%$ da produção total e o experimento foi encerrado.
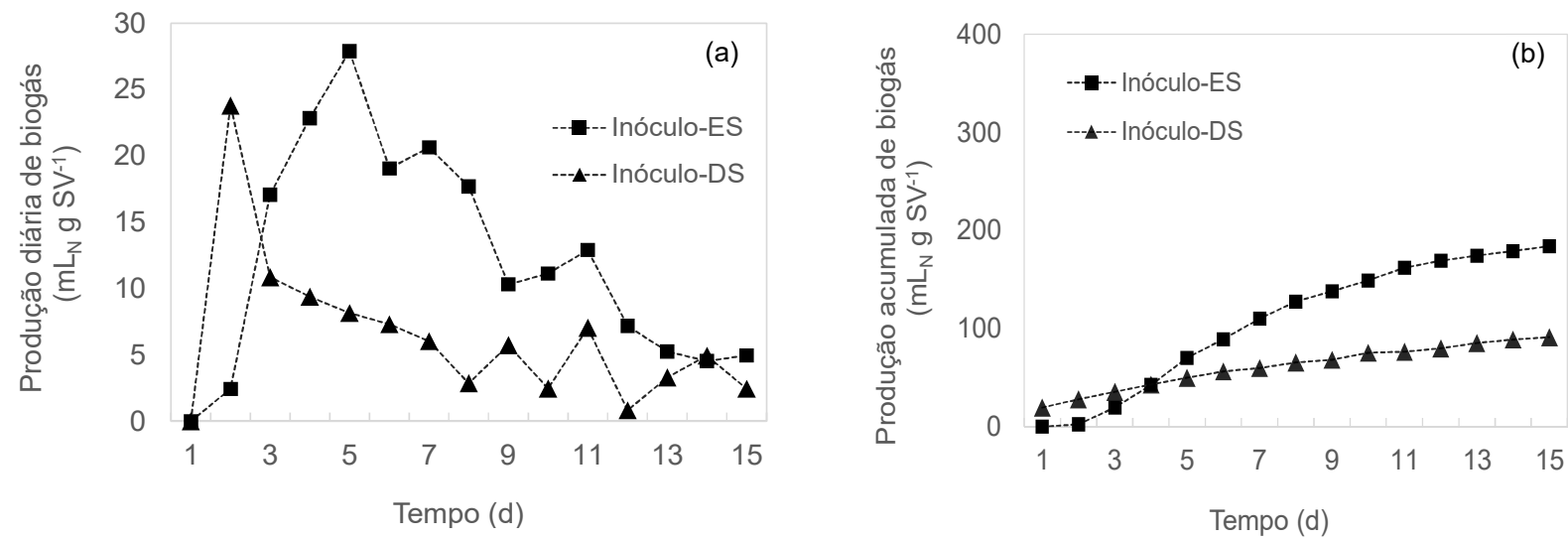

Figura 2: Produção diária (a) e acumulada (b) de biogás referente aos inóculos 1 e 2.

Os RFH apresentaram produção acumulada de biogás semelhante, independentemente do tipo de inóculo utilizado. A produção acumulada de biogás dos RFH incubados com o inóculo/ES foi de $362 \mathrm{~mL} \mathrm{~L}_{\mathrm{N}} \mathrm{SV}$ ${ }^{1}$ e com a utilização do inóculo/DS foi de $348 \mathrm{~mL}_{\mathrm{N}} \mathrm{g} \mathrm{SV}^{-1}$ (Figura 3). No entanto, observou-se que o comportamento da curva de produção de biogás ao longo do tempo foi distinto em relação ao tipo de inóculo testado, ainda que a massa de sólidos voláteis do inóculo em relação à massa de sólidos voláteis do substrato (relação I/S) foi similar, sendo 4.0 para o inóculo/ES e 4,1 para o inóculo/DS (Tabela 1). A utilização do inóculo/ES possibilitou a rápida conversão da matéria orgânica em biogás, com aproximadamente $90 \%$ da produção total gerada nos primeiros quatro dias de incubação, seguida de uma tendência à estabilização após este período. 


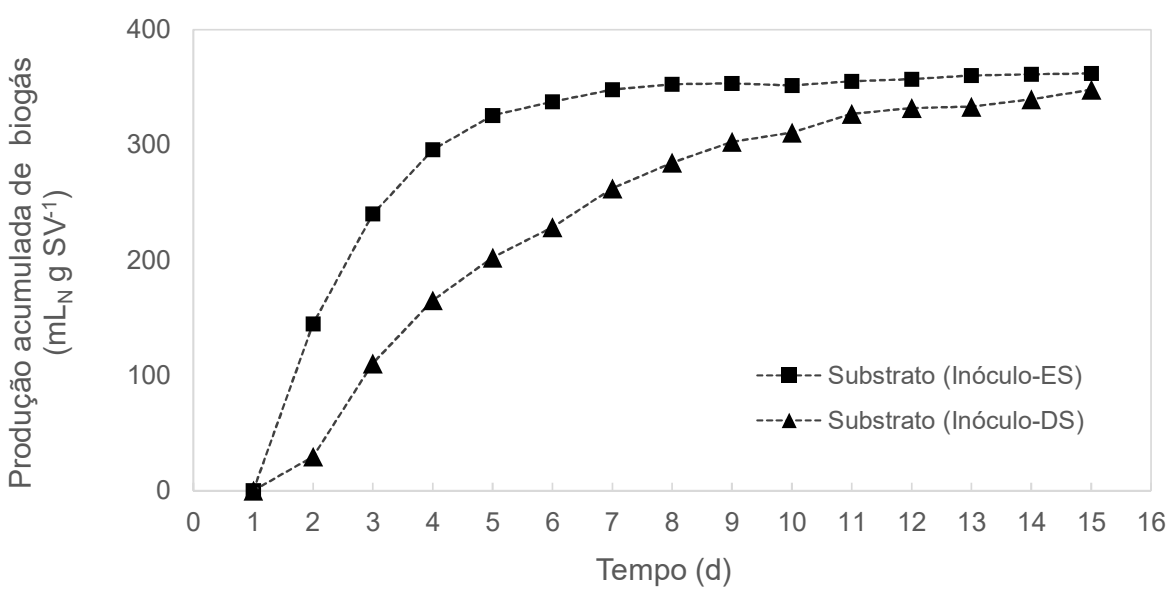

Figura 3: Produção acumulada de biogás para o substrato com os inóculos 1 e 2.

Este comportamento pode ter sido gerado em função da variedade microbiana presente em lodo de estações de tratamento de esgoto sanitário, tornando-o mais adaptado à degradação de substratos de composição orgânica diversa em termos de carboidratos, proteínas e lipídeos. Este tipo de comportamento é o que se espera de um reator em escala real de operação, onde a rápida conversão da matéria orgânica em biogás resulta em menores requisitos de área e tempo de digestão.

A produção acumulada de biogás utilizando o inóculo/DS como fonte bacteriana foi semelhante ao inóculo/ES. Porém, para este ensaio foram necessários dez dias para que $90 \%$ da produção total fosse obtida. Este comportamento pode ter ocorrido devido à homogeneidade das características do efluente que alimenta o biodigestor da suinocultura. Os dejetos suínos são gerados com certo nível de uniformidade quanto à composição, o que requer maior tempo de adaptação para a biodigestão de substratos com composição variada, como os RFH.

\section{Composição do biogás}

A composição do biogás foi determinada com o objetivo de quantificar as concentrações de metano $\left(\mathrm{CH}_{4}\right)$, dióxido de carbono $\left(\mathrm{CO}_{2}\right)$ e sulfeto de hidrogênio $\left(\mathrm{H}_{2} \mathrm{~S}\right)$ (Figura 4). Observou-se que, ao contrário da produção acumulada, a composição do biogás foi influenciada pelo tipo de inóculo utilizado. A maior influência foi observada quanto ao teor de metano, uma vez que os testes com o inóculo/DS apresentaram concentração de metano de $60 \%$ (com produção de metano de $210 \mathrm{~mL}_{\mathrm{N}} \mathrm{CH}_{4} \mathrm{~g} \mathrm{SV}^{-1}$ ) e os testes com inóculo/ES apenas 51\% (com produção de metano de $184 \mathrm{~mL}_{\mathrm{N}} \mathrm{CH}_{4} \mathrm{~g} \mathrm{SV}^{-1}$ ).

Tal diferença pode ser atribuída aos valores de $\mathrm{pH}$ e alcalinidade levemente abaixo do recomendado para a biodigestão anaeróbia, haja vista que tais parâmetros refletem diretamente nas condições ideais do ambiente anaeróbio para a bioconversão da matéria orgânica. Jiang et al. (2012) ao avaliar o PME de RFH compostos por $75 \%$ feijão, $19 \%$ milho, $3 \%$ cenoura e $3 \%$ brócolis reportaram potencial de $350 \mathrm{~L}_{\mathrm{N}} \mathrm{CH}_{4} \mathrm{~kg} \mathrm{SV}^{-}$ 1 , indicando que a composição de RFH utilizada tem influência direta no PME. 


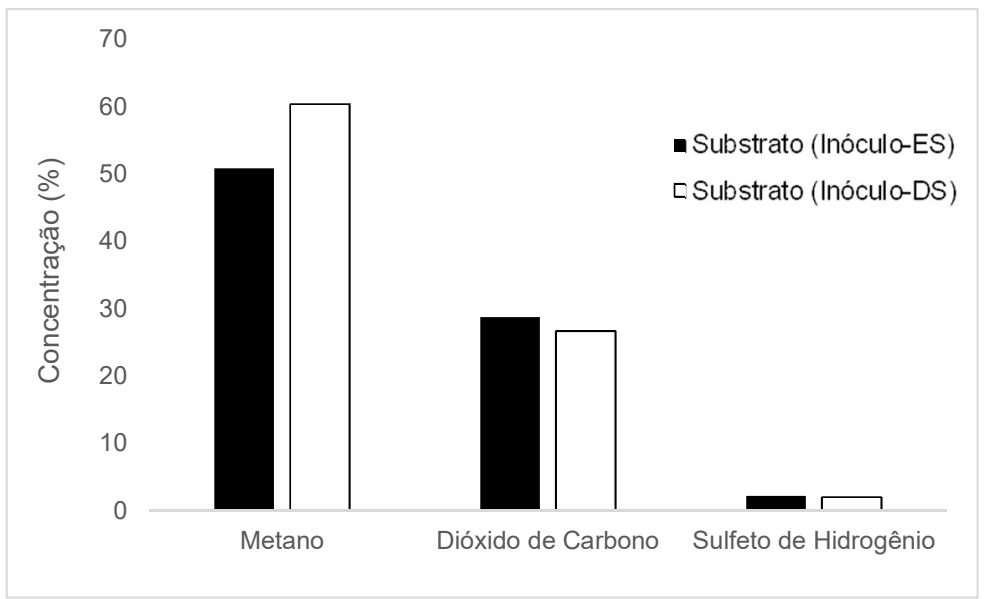

Figura 4: Composição do biogás a partir dos inóculos avaliados.

\section{CONCLUSÕES}

Os RFH apresentam pH ácido e elevado teor de umidade e de sólidos voláteis. Os dois inóculos testados apresentaram diferentes características, principalmente quanto à alcalinidade total. A produção acumulada de biogás ( $\mathrm{mL}_{\mathrm{N}}$ biogás $\mathrm{g} \mathrm{SV}^{-1}$ ) dos RFH utilizando as duas fontes de inóculos não apresentou diferença expressiva. No entanto, foram observadas diferentes velocidades de conversão da matéria orgânica e teor de metano na composição do biogás. O inóculo/ES permitiu a geração de $90 \%$ da produção acumulada de biogás em um período de tempo 50\% inferior. No entanto, o inóculo/DS apresentou teor de metano 19\% superior. Desta maneira, observou-se que mesmo com maior capacidade de degradação durante o processo, o inóculo/DS permitiu uma produção acumulada de metano $\left(\mathrm{mL}_{\mathrm{N}} \mathrm{CH}_{4} \mathrm{~g} \mathrm{SV}^{-1}\right)$ 14\% maior. Mesmo considerando tais informações preliminares, novas investigações são necessárias utilizando maior número de repetições para avaliar os efeitos nos RFH.

\section{REFERÊNCIAS}

APHA. American Public Health Association. Standard methods for the examination of water and wastewater. 21 ed. Washington: American Water Works Association, 2005.

ASTM. American Society for Testing and Materials. D1945-14: Standard Test Method for Analysis of Natural Gas by Gas Chromatography. West Conshohocken: ASTM International, 2014.

BOUALLAGUI, H.; LAHDHEB, H.; ROMDAN, E. B.; RACHDI, B.; HAMDI, M.. Improvement of fruit and vegetable waste anaerobic digestion performance and stability with cosubstrates addition. Journal of Environmental Management, v.90, n.5, p.1844-1849, 2009.

BRASIL. Lei 12.305: Política Nacional de Resíduos Sólidos. Brasília: Presidência da República, 2010.

DIN. Deutsches Institut fur Normung. DIN 38414: Determination of the amenability to anaerobic digestion: Sludge and Sediments (group S). Berlin, 1985.

FORSTER-CARNEIRO, T.; PEREZ, M.; ROMERO, L. I.. Influence of total solid and inoculum contents on performance of anaerobic reactors treating food waste. Bioresource Technology, v.99, n.15, p.6994-7002, 2008.

GOMEZ-LAHOZ, C.; FERNÁNDEZ-GIMÉNEZ, B.; GARCIAHERRUZO, F.; RODRIGUEZ-MAROTO, J. M.; VEREDA-ALONSO, C.. Biomethanization of mixtures of fruits and vegetables solid wastes and sludge from a municipal wastewater treatment plant. Journal of Environmental Science and Health, v.42, n.4, p.481-487, 2007.

HOLLIGER, C.; ALVES, M.; ANDRADE, D.; ANGELIDAKI, I.; ASTALS, S.; BAIER, U.; BOUGRIER, C.; BUFFIÈRE, P.; CARBALLA, M.; WILDE, V.; EBERTSEDER, F.; FERNÁNDEZ, B.; FICARA, E.; FOTIDIS, I.; FRIGON, J. C.; LACLOS, H. F.; GHASIMI, D. S.; HACK, G.; HARTEL, M.; HEERENKLAGE, J.; HORVATH, I. S.; JENICEK, P.; KOCH, K.; KRAUTWALD, J.; LIZASOAIN, J.; LIU, J.; MOSBERGER, L.; NISTOR, M.; OECHSNER, H.; OLIVEIRA, J. V.; PATERSON, M.; PAUSS, A.; POMMIER, S.; PORQUEDDU, I.; RAPOSO, F.; RIBEIRO, T.; RÜSCH P. F.; STRÖMBERG, S.; TORRIJOS, M.; VAN EEKERT, M.; VAN LIER, J.; WEDWITSCHKA, H.; WIERINCK, I.. Towards a standardization of biomethane potential tests. Water Science \& Technology, v.74, n.11, p.2515-2522, 2016. 
JIANG, Y.; HEAVE, S.; BANKS, C. J.. Strategies for stable anaerobic digestion of vegetable waste. Renewable Energy, v.44, p.206-214, 2012.

KIEHL, E. J.. Novos Fertilizantes Orgânicos. Piracicaba: Degaspari, 2010.

LI, Y.; ZHANG, R.; LIU, G.; CHEN, C.; HE, Y.; LIU, X.. Comparison of methane production potential, biodegradability, and kinetics of different organic substrates. Bioresource Technology, v.149, n.63, p.565-569, 2013.

LIN, J.; ZUO, J.; GAN, L.; LI, P.; LIU, F.; WANG, K.; CHEN, L.; GAN, H.. Effects of mixture ratio on anaerobic co-digestion with fruit and vegetable waste and food waste of China. Journal of Environmental Sciences, v.23, n.8, p.1403-1408, 2011.

MALAVOLTA, E.. ABC da adubação. 5 ed. São Paulo: Agronômica Ceres, 1989.

NEVES, L.; OLIVEIRA, R.; ALVES, M.. Anaerobic co-digestion of coffee waste and sewage sludge. Waste Management, v.26, n.2, p.176-181, 2006.

PETRIC, I.; HELIC, A.; AVDIC, E.. Evolution of process parameters and determination of kinetics for co-composting of organic fraction of municipal solid waste with poultry manure. Bioresource Technology, v.117, p.107-116, 2012.

RABL, A.; SPADARO, J. V.; ZOUGHAIB, A.. Environmental impacts and costs of solid waste: a comparison of landfill and incineration. Waste Management \& Research, v.26, p.147162, 2008.

RAPOSO, F.; LA RUBIA, M. A.; FERNÁNDEZ-CEGRÍ, V.; BORJA, R.. Anaerobic digestion of solid organic substrates in batch mode: An overview relating to methane yields and experimental procedures. Renewable and Sustainable Energy Reviews, v.16, n.1, p.861-887, 2011

RIPLEY, L. E.; BOYLE, W. C.; CONVERSE, J. C.. Improved alkalimetric monitoring for anaerobic digestion of highstrength wastes. Journal Water Pollution Control Federation, v.58, n.5, p.406-411, 1986.

STRÖMBERG, S.; NISTOR, M.; LIU, J.. Towards eliminating systematic errors caused by the experimental conditions in Biochemical Methane Potential (BMP) tests. Waste Management, v.34, n.11, p.1939-1948, 2014.

VDI. Verein Deutscher Ingenieure. VDI 4630: Fermentation of organic materials Characterisation of the substrate, sampling, collection of material data, fermentation tests. Düsseldorf, 2006.

WARD, A. J.; HOBBS, P. J.; HOLLIMAN, P. J.; JONES, D. L.. Optimisation of the anaerobic digestion of agricultural resources. Bioresource Technology, v.99, n.17, p.7928-7940, 2008.

YEN, H.; BRUNE, E.. Anaerobic co-digestion of algal sludge and waste paper to produce methane. Bioresource Technology, v.98, n.1, p.130-134, 2006.

A CBPC - Companhia Brasileira de Produção Científica (CNPJ: 11.221.422/0001-03) detém os direitos materiais desta publicação. Os direitos referem-se à publicação do trabalho em qualquer parte do mundo, incluindo os direitos às renovações, expansões e disseminações da contribuição, bem como outros direitos subsidiários. Todos os trabalhos publicados eletronicamente poderão posteriormente ser publicados em coletâneas impressas sob coordenação da Sustenere Publishing, da Companhia Brasileira de Produção Científica e seus parceiros autorizados. Os (as) autores (as) preservam os direitos autorais, mas não têm permissão para a publicação da contribuição em outro meio, impresso ou digital, em português ou em tradução. 